\title{
Unexpected Risks for Campers and Hikers: Tick-Borne Infections
}

\author{
Gökcen Dinc ${ }^{1,2}$, Hayati Demiraslan³, Mehmet Doganay, ${ }^{3,4 *}$ \\ ${ }^{1}$ Department of Medical Microbiology, Faculty of Medicine, Erciyes University, 38039, Kayseri, Turkey \\ ${ }^{2}$ Genome and Stem Cell Center (GENKOK), Department of Molecular Microbiology, University of Erciyes, 38039, Kayseri, Turkey \\ ${ }^{3}$ Department of Infectious Disease and Clinical Microbiology, Faculty of Medicine, Erciyes University 38039, Kayseri, Turkey \\ ${ }^{4}$ Erciyes University Vectors and Vector-borne Diseases Research and Implementation Center 38039, Kayseri, Turkey
}

Corresponding Author: Mehmet Doganay, M.D., Professor of Infectious Diseases, Department of Infectious Diseases, Faculty of Medicine, Erciyes University, 38039-Kayseri, Turkey. Tel: +90 533368 2042, Email: mdoganay@erciyes.ed.tr

Received October 18, 2016; Accepted December 5, 2016; Online Published February 19, 2017

\begin{abstract}
Introduction: Camping and hiking are popular worldwide recreational activities. All age groups, elderly or young, immunocompetent or immunosupressive people may engage in these activities. During these activities, individuals may get injured or be exposed to pathogens. There is also a strong possibility of experiencing mosquito, lice, or tick bites, bee stings, or being bitten by scorpions, snakes, rodents, wild or feral animals. This study reviewed the current literature regarding tick-borne infections encountered during recreational activities.

Methods: PubMed and the Web of Science databases were searched for the keywords "campers," "hikers," and "tick borne infections." Major reviews, research papers, and case series on campers and hikers were reviewed, and current articles for tickborne infections were selected and summarized.

Results: People who engage in recreational activities are potentially at risk for infection from environmental sources. A group of important vector-borne diseases is tick-borne infections, the major agents of which are Babesia spp., Borrelia spp., Rickettsia spp., Ehrlichia spp., Francisella tularensis, Coxiella burnetii, Crimen-Congo hemorrhagic fever (CCHF), and tick-borne encephalitis (TBE) viruses. These infections have a widespread geographical distribution.

Conclusion: Participating in outdoor recreational activities is increasing all over the world. While partaking in these activities, humans are frequently exposed to ticks and are potentially at risk for infection. To prevent infection, public and medical awareness is necessary.

Keywords: Campers, Hikers, Tick-borne infections
\end{abstract}

Citation: Dinc G, Demiraslan H, Doganay M. Unexpected risks for campers and hikers: tick-borne infections. Int J Travel Med Glob Health 2017;5(1):5-13. doi:10.15171/ijtmgh.2017.02.

\section{Introduction}

Travelling, hiking, and camping are common recreational activities in which participation is currently increasing throughout the world. Travelers, hikers, and campers may be exposed to various kinds of infections either during their journey or upon arrival at their final destination. These infections may be transmitted by food, water, vector or direct contact with contaminated material or animal bites. Table 1 summarizes general recreational activities and associated infection risks. ${ }^{1,2}$ The most common vector-borne diseases transmitted during recreational activity are tick-borne infections caused by microorganisms such as Francisella tularensis, Coxiella burnetii, Borrelia spp., Ehrlichia spp., Rickettsia spp., Babesia spp., Crimen-Congo hemorrhagic fever (CCHF), and tick-borne encephalitis (TBE) viruses
(Table 2)..$^{1-3}$

Ticks are arachnids that feed on the blood of a vertebrate once during each developmental stage to acquire the nutrients they need for their metamorphosis. ${ }^{4}$ The life cycle of ticks usually includes four periods: the egg, larva, nymph, and adult periods. After hatching from eggs, ticks need to feed on blood at every stage of life in order to survive. Ticks require many hosts to complete their full life cycle (up to 3 years). Most ticks die from being unable to catch a new host for feeding. Ticks feed on the blood of mammals, birds, or coldblooded animals. If the host is infected with a bloodborne infection, the tick ingests the pathogen through the blood. The pathogen can then be transmitted to a new susceptible host (Figures 1 and 2). Tick activity changes in a seasonal pattern with increasing temperatures. This leads to increased 
Table 1. General Recreational Activities and Associated Infection Risks ${ }^{a}$

\begin{tabular}{|c|c|c|}
\hline Activity & Source of Infection & Transmission \\
\hline Travel & $\begin{array}{l}\text { Endemic / epidemic geographical or tropical } \\
\text { areas }\end{array}$ & Oral or respiratory route \\
\hline Keeping pets, zoo park or farm visit & Wild animals or livestock & Animal contact / animal bites \\
\hline $\begin{array}{l}\text { Outdoor activities: camping, trekking, and } \\
\text { picnics etc. }\end{array}$ & Animals, water, infected vectors & $\begin{array}{l}\text { Animal bites, vector bites, drinking contaminated } \\
\text { water, inhaling contaminated materials }\end{array}$ \\
\hline Contact with contaminated water & Contaminated pool or fresh water & $\begin{array}{l}\text { Bathing, drinking, aerosol, or aspiration of } \\
\text { contaminated water }\end{array}$ \\
\hline Sport games: wrestling, boxing, football, etc. & Infected body secretions and blood & $\begin{array}{l}\text { Contact with skin lesion, blood, or through the } \\
\text { respiratory route }\end{array}$ \\
\hline
\end{tabular}

a Modified from references 1, 2, and 3 .

Table 2. Major Tick-Borne Infections and Etiological Agents

\begin{tabular}{ll}
\hline Agents & Disease \\
\hline Francisella tularensis & Tularemia \\
Borrelia burgdorferi & Lyme borreliosis \\
$\begin{array}{l}\text { Borrelia spp. (most commonly } \\
\text { Borrelia hermsii and Borrelia }\end{array}$ & Tick-borne relapsing fever \\
turicata) & Human monocytotropic \\
Ehrlichia chaffeensis & ehrlichiosis \\
\hline Ehrlichia ewingii & Human granulocytic ehrlichiosis \\
Anaplasma phagocytophilum & Human granulocytic anaplasmosis \\
Rickettsia conorii & Boutonneuse fever \\
Rickettsia sibirica & Siberian tick typhus \\
Rickettsia australis & Queensland tick typhus \\
\hline Babesia species & Babesiosis \\
Nairovirus & Crimean-Congo hemorrhagic fever \\
Coltivirus & Colorado tick fever \\
Flavivirus & TBE/meningoencephalitis \\
\hline
\end{tabular}

Abbreviation: TBE, tick-borne encephalitis.

risk of human exposure to ticks in infested areas during warm weather seasons. Ticks can live at altitudes up to $2383 \mathrm{~m}$. The geographic distributions of tick species are varied throughout the world. ${ }^{5-7}$

Currently, tick-borne infections such as CCHF, tularemia, and lyme are emerging or re-emerging in some parts of the world. Outbreaks have been seen in the Eurasia region, particularly in Turkey, Iran, Russia, Pakistan, Afghanistan, and in other parts of the northern hemisphere and Africa. ${ }^{5}$

The present paper reviewed the health risks from recreational activities and exposure to pathogenic microorganisms during camping and hiking activities. The most common tickborne infections seen in Turkey and nearby geographical areas have also been considered.

\section{Methods}

The data for this narrative review was collected from searches of PubMed and Web of Science databases for reviews or original articles about tickborne infections. Searches were performed during August and September 2016 using keywords such as "campers," "hikers," and "tickborne infections." The database search was limited to articles written in English, and authors generally used articles written later than 2010 and recently published textbooks about infectious diseases and

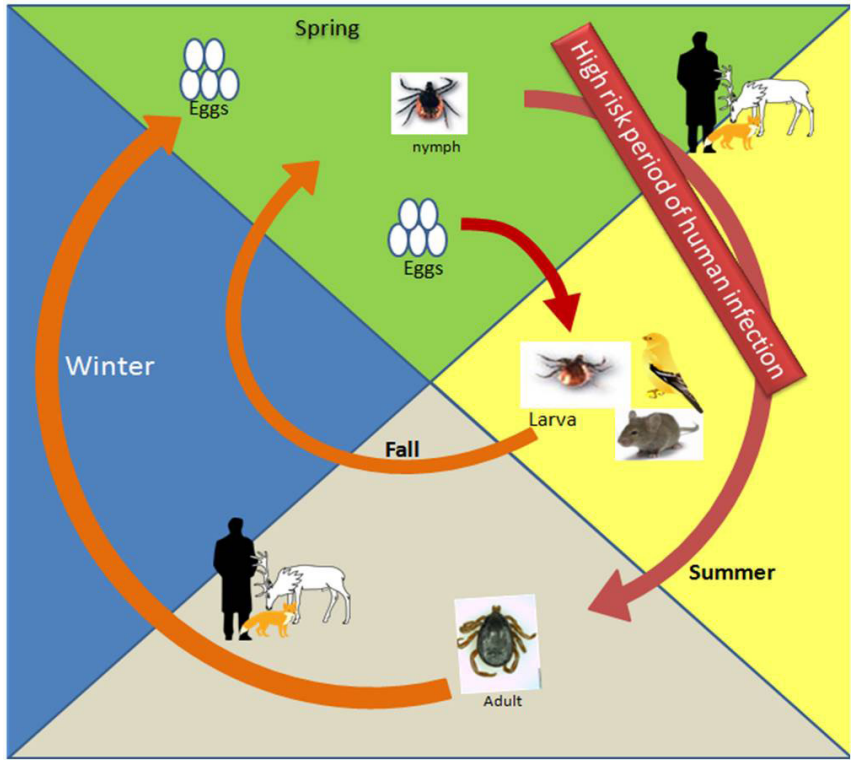

Figure 1. Life cycle of ticks in nature (modified from references 5 and 6).

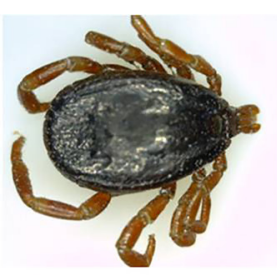

A. Dermacentormarginatus

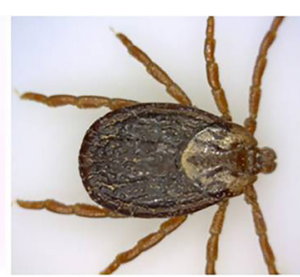

B. Hyalomma marginatum

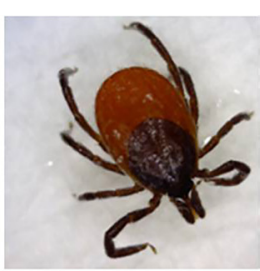

C. Ixodes ricinus
Figure 2. Most Commonly Seen Tick Species That Transmit Pathogens To Humans. (A) Dermacentor marginatus, (B) Hyalomma marginatum, (C) Ixodes ricinus.

Picture was kindly supplied by Professor Abdullah Inci from the Department of Parasitology, Veterinary Faculty of Erciyes University, Kayseri/Turkey.

zoonoses. A total of 64 references were used for this article. Some clinical data and photos of patients and ticks from an infectious disease clinic and research center were used. The epidemiologic and transmission characteristics of tickborne infections were the focus of this review.

\section{Results}

The search for keywords "tick-borne infections" provided 
27498 manuscripts on PubMed Central and 4951 manuscripts on Web of Science; "campers" provided 226 manuscripts on PubMed and 429 manuscripts on Web of Science; "hikers" provided 136 manuscripts on PubMed and 484 manuscripts on Web of Science; "tick-borne infections and campers" provided 5 manuscripts on PubMed and 1 manuscript on Web of Science; "tick-borne infections and hikers" provided 3 manuscripts on PubMed and 2 manuscripts on Web of Science. Ultimately, 55 articles and 6 chapters from 4 books which had content closely related to major tick-borne infections were used for this paper. Relevant, up-to-date data from the web pages of the Centers for Disease Control and Prevention (CDC) and the World Health Organization (WHO) was also used. All data was divided into groups of bacterial and viral diseases and prevention and control.

\section{Bacterial Infections}

\section{Tularemia}

The aetiologic agent of tularemia is Francisella tularensis, a gram-negative and facultative intracellular small coccobacillus. There are four known subspecies: F. tularensis, subsp. tularensis (type A), subsp. holarctica (type B), subsp. mediasiatica, and subsp. novicida. Type A isolates are generally isolated from North America; among these subspecies, type A contains the most infectious strains. Type B isolates are widely seen in North America and Eurasia, and F. t. mediasiatica is found in central Asia. Type A and type B strains are highly virulent for humans., ${ }^{2,8}$ Tularemia is seen throughout the Northern hemisphere, whereas F. tularensis is known as a highly infectious bacterium where exposure to at least 10 organisms is enough for a disease to develop in humans. This agent is a Tier 1 (Category A) bioterror agent on the CDC list, because low doses can lead to fatal diseases. ${ }^{8-10}$

Francisella tularensis is found widely in nature and has been identified in almost 250 wildlife species, including more than 50 species of arthropods. There are several potential vectors that transmit $F$. tularensis to humans, and wild rodents and lagomorphs are natural reservoirs of this agent. Humans may become infected through various routes, including direct contact with an infected animal, consumption of infected food or water, inhalation of infected aerosols, or through the bite of an arthropod such as ticks (Dermacentor variabilis, Amblyomma americana), tabanid/deer flies (Chrysops discalis), mosquitoes (especially Aedes cinereus), fleas, lice, midges, or mites (Figure 3). Only rarely it is transmitted from person to person. ${ }^{8,11-13}$

Tularemia has been reported in people living in rural areas in endemic regions. If campers or hikers stay in these areas, they may get infected. Leisure activities such as tracking, hunting, or fishing may put a person at risk for tularemia in endemic areas. Activities in contaminated water are other risk factors. ${ }^{13,14}$ Tick-borne tularemia is rarely reported, but it is probably underestimated or not identified among hikers or campers.

The agent enters the body through the skin, conjunctiva, oropharynx, respiratory or gastrointestinal tract. The incubation period is generally 3 to 5 days (1-14 days). The 6 clinical forms of tularemia that have been described in humans are ulceroglandular, glandular, oculoglandular, oropharyngeal, typhoidal, and pneumonic (Figure 4). The ulceroglandular

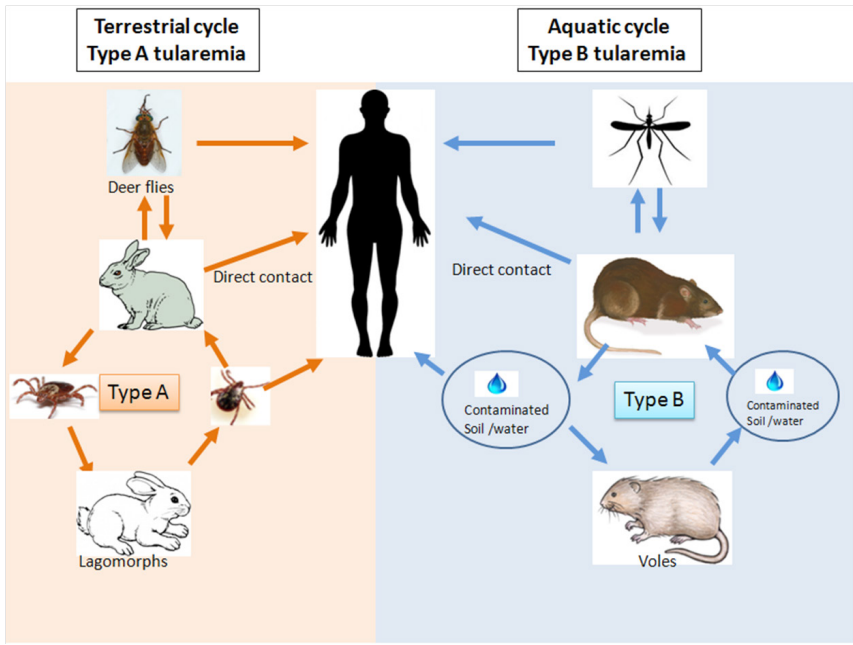

Figure 3. Transmission of Tularemia to Human by Ticks and the Life Cycle of Francisella tularensis in Nature.

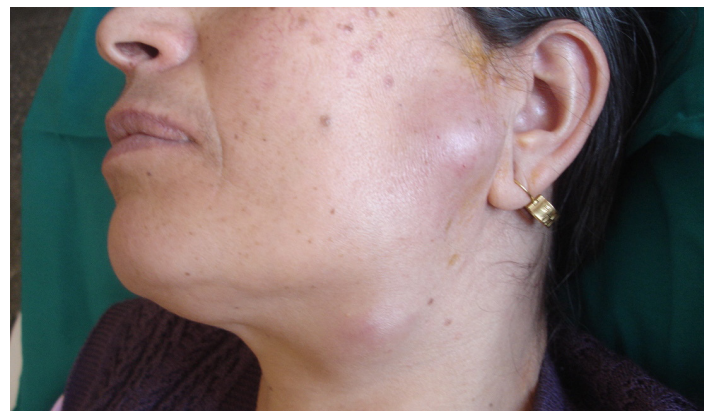

Figure 4. A Female Patient With Oculoglandular Tularemia. Patient's picture shows typical appearance of preauricular and submandibular lymphadenomegalia.

form is the most common form in the endemic regions; however, the oropharyngeal form is the form most commonly seen in Turkey. ${ }^{10,13-15}$ In ulceroglandular tularemia, a tick bite or direct contact with an infected animal plays a role in the development of the infection. The oropharyngeal form of tularemia occurs from the consumption of contaminated food or water. In this form, patients have a sore throat and cervical adenopathy. Typhoidal tularemia has the highest mortality rates, and lymphadenopathy is rarely observed. Pneumonic tularemia occurs through the inhalation of infective aerosol or as a secondary complication of other clinical forms. , $^{2,313,14}$

A diagnosis of tularemia should be considered in patients with skin lesion, lymphadenopathy, fever, and splenomegaly. Diagnosis based on clinical examination should be confirmed with laboratory tests. For the defined diagnosis of tularemia, culture, serological analysis (agglutination, enzyme-linked immunosorbent assay [ELISA], direct fluorescent antibody staining), and PCR-based molecular techniques are useful. Typhoid fever, paratyphoid fever, psittacosis, brucellosis, cat scratch disease, Q fever, and malaria should be considered for differential diagnoses. ${ }^{3,9}$

For treatment, gentamicin or streptomycin administered for 10 days is the first choice in severe forms of tularemia infection. Doxycycline or ciprofloxacin given for at least 2 weeks may be used for less severe tularemia infections; 
post-exposure prophylactic antibiotic treatment is not suggested since human-to-human transmission has not been observed. ${ }^{1,3,13}$

\section{Lyme Disease (Lyme Borreliosis)}

Lyme borreliosis is a multipathogen and multihost disease that shows zoonotic characteristics due to transmission to humans by ticks. Lyme disease was first observed in 1977 in a group of children from Lyme, Connecticut, USA with rheumatoid arthritis-like symptoms. In the autumn of 1981, Borrelia burgdorferi sensu lato was isolated from Ixodes scapularis ticks in North America. Lyme borreliosis has a wide geographic distribution and a broad host range of vectors and bacteria. This tick-borne disease is generally seen in the Northern Hemisphere (especially North America, Europe, and Asia) from May to August, the months in which human recreational activities and nymph tick activities are the most intense. Infection may be seen in humans of any age that are at risk for tick bites. Lyme disease is a frequently seen tick-borne infection in the Northern Hemisphere. ${ }^{16-20}$

Borrelia burgdorferi sensu lato is a group of spirochete bacteria that has been identified in at least 19 species: B. burgdorferi sensu stricto, $B$. bavariensis, $B$. tanukii, $B$. bissettii, B. sinica, B. garinii, B. yangzte, B. afzelii, B. japonica, B. finlandensis, $B$. lusitaniae, B. carolinensis sp. nov., B. andersonii, B. turdi, $B$. spielmanii, B. americana, B. californiensis, B. kurtenbachii, and B. valaisiana.$^{17}$ B. burgdorferi sensu lato is transmitted to wild animal hosts (rodents, other mammals, birds) and to humans by the Ixodes ricinus species of hard ticks, I. ricinus in Europe, I. persulcatus in Asia, I. scapularis in the Northeastern and Upper Midwestern USA, and I. pacificus on the west coast of the Unites States. ${ }^{19,21,22}$ Ixodes ricinus has a four-stage life cycle: egg, larva, nymph, and adult. Only female ticks feed on blood from a vertebrate host at every active stage, and B. burgdorferi transmission occurs through saliva during the bite. However, larval ticks are not significant as a vector, because transovarial transmission is rare. Human beings are infected from adult or nymphs tick bites. ${ }^{3,23,24}$ Rodents (rat, wood rat, mouse, dormouse, vole, wood squirrel, and chipmunk), insectivores (shrew and hedgehog), raccoon, and several bird species may be reservoirs for B. burgdorferi. The transmission of Lyme disease by mosquitoes, flies, or fleas is not proven., ${ }^{3,19}$

Lyme borreliosis is a complex systemic illness that includes various symptoms related to the skin, heart, nervous system, and musculoskeletal system. The most common clinical symptom is erythema migrans for localized infection. There are three main stages of Lyme disease. The first and second stages are considered in early infection and the third stage is defined as the late infection..$^{23-25}$

The history of tick-bite provides important clues and geographical data helpful in diagnosing Lyme borreliosis. A clinical diagnosis should be confirmed with microbiologic or serological investigations. Lyme borreliosis antibodies may not be detected in the early stages. Therefore, a serological test should be performed 2-6 weeks after acquiring the disease. ${ }^{18,24}$ Many serological methods are useful for diagnosis, including immunofluorescence, hemagglutination, ELISA, and immunoblotting. Western blotting may be used to identify the first test results, because ELISA and indirect fluorescein antibody test kits have low sensitivity (26\% to $57 \%$ ). These serological investigations are essential, although some problems are associated with the test results, including a falsepositivity of IgM response or borrelial antibodies remaining for years after infection..$^{18}$ Although culture and molecularbased techniques may be used for laboratory diagnoses, specialized laboratories are needed. Microorganisms are identified by culture or PCR-based assays using lesional skin, endomyocardial biopsy, cerebrospinal fluid, synovia, or blood depending on the form of the disease. B. burgdorferi isolation is difficult and takes a lot of time. PCR-based assays have more sensitivity and specificity, but interlaboratory differentiation is present in the results. Differential diagnoses should be evaluated according to the form or stage of Lyme borreliosis. ${ }^{1,21}$

Medical therapy choices depend on the stage of the Lyme borreliosis. Doxycycline, amoxicillin, and third-generation cephalosporins are the most commonly used antibiotics. To treat early infection, doxycycline or amoxicillin may be used for 14-21 days. If the patient is allergic to these antibiotics, azithromycin (for 5 days) or cefuroxime acetyl (for 14-21 days) can be used. ${ }^{18}$ Doxycycline or amoxicillin for 30-40 days is recommended for patients with arthritis and/or acrodermatitis. If acute neuroborreliosis occurs, ceftriaxone may be used for $14-21$ days. $^{21}$

\section{Ehrlichioses}

Human ehrlichioses is an emerging zoonotic bacterial disease that is caused by Ehrlichia chaffeensis in humans and is a causative agent of human monocytic ehrlichioses (HME), an acute febrile tick-borne infection; however, the term 'ehrlichioses' can be used for human infections of Anaplasmataceae family members, especially E. chaffeensis, Anaplasma phagocytophilum, Ehrlichia ewingii and Ehrlichia muris-like. ${ }^{26,27} \mathrm{~A}$. phagocytophilum is a causative agent of human granulocytic anaplasmosis which was previously defined as human granulocytic ehrlichioses (HGE). E. ewingii is an etiologic agent of granulocytic ehrlichiosis in humans, dogs, and deer. These zoonotic pathogens need a mammalian reservoir and an arthropod vector for their life cycle as they are transmitted to humans through infected tick bites. While Ixodes ricinus and I. persulcatus are the vectors for Ehrlichia spp. and A. phagocytophilum in Europe and Asia, respectively, Amblyomma americanum (Lone Star tick), I. scapularis, and I. pacificus ticks are the vectors of these agents in the United States. $^{27}$

Ehrlichia spp. are obligate intracellular bacteria in the genus of Ehrlichia, and this agent infects mononuclear phagocytic cells. ${ }^{26}$ The A. americanum is the main vector of E. chaffeensis and E. ewingii; transstadial transmission of these agents occurs among ticks. Deer (especially white-tailed deer; Odocoileus virginianus), red foxes (Vulpes vulpes), horses, cattle, sheep, goats, dogs, and rodents are reservoirs for these agents. ${ }^{28}$

When a tick bites a human, E. chaffeensis and E. ewingii spread through the body via the bloodstream and lymphatics within an incubation period of 5 to 21 days. ${ }^{27} \mathrm{HME}$ occurs in the clinical spectra of asymptomatic or moderate to severe disease. However, severe diseases can result in death. HME patients present symptoms such as fever (often $>39^{\circ} \mathrm{C}$ ), rash (especially in children and HIV positive adults), headache, myalgia, arthralgia, anorexia, or nausea. A skin rash develops 
on the extremities within the first week of infection. ${ }^{1,29}$ Anemia, leukopenia, thrombocytopenia, or lymphopenia may also be present. Children with HME infection may present with peripheral edema more often than adults experiencing the same infection. ${ }^{27}$ Lymphadenopathy, pharyngitis, cough, diarrhea, abdominal pain, and mental disorders may occur less often, and these clinical manifestations present specifically in the multisystemic disease of HME patients. ${ }^{27,29}$ Myocardial dysfunction, hepatic failure, acute renal failure, adrenal failure, and disseminated intravascular coagulopathy may develop in the multisystemic form of HME. Approximately $20 \%$ of all HME patients may have a neurological finding such as meningitis or encephalopathy syndromes. HGE and human E. ewingii infections have similar clinical manifestations, and E. ewingii is less virulent than E. chaffeensis. ${ }^{2,26,27,29}$

Clinical manifestations with a history of tick bite may be useful for the diagnosis of ehrlichioses. A definitive diagnosis should be obtained with laboratory tests including staining of peripheral blood or bone marrow smears to detect morulae in granulocytes or monocytes, serologic testing of specific $\operatorname{IgM}$ and IgG antibodies with indirect immunofluorescence assay (IFA), or detection of Ehrlichia spp. DNA by PCR. Infections caused by E. chaffeensis, A. phagocytophila, E. ewingii and Rickettsia rickettsii should be considered together for differential diagnoses. ${ }^{26,29}$

For HME and HGE, doxycycline administered orally for 10-14 days is the treatment of choice. ${ }^{27}$

\section{Rickettsioses}

Rickettsiae occur between bacteria and viruses. They are obligate intracellular gram-negative coccobacillary that stain weakly with gram stain, but they have a gram-negative cell wall. Rickettsial microorganisms are categorized into the spotted fever group (SFG) and the typhus and scrub typhus groups. ${ }^{30}$ The typhus group was not included in this review as it is transmitted by vectors other than ticks. Rickettsioses are one of the oldest well-known zoonoses, and during the past 30 years, many new rickettsioses have been described by new diagnostic tools. ${ }^{31}$ SFG rickettsiae include $R$. rickettsii that cause Rocky Mountain spotted fever (RMSF), R. parkeri, and Rickettsia species 364D. ${ }^{32,33}$ Mammals and arthropods are natural hosts of rickettsiae which are incidentally transmitted to humans by arthropods. The prevalence of rickettsial disease is related to the distribution of their vectors as well as human activities that are high risk for tick exposure, such as camping and hiking. ${ }^{32}$

The rickettsial pathogens are commonly found throughout the world in such distributions as Africa, Europe, and Asia, (R. aeschlimannii), Africa, America, the Pacific Islands, and Asia ( $R$. africae) (African tick-bite fever), R. conorii (Mediterranean spotted fever), and $R$. rickettsii (Rocky Mountain spotted fever). ${ }^{34}$

The clinical presentation of the disease varies from selflimited illnesses to life-threatening infections. Classical clinical manifestations of rickettsiosis are fever, rash, and headache; eschar (touché noir) may also be observed. ${ }^{31}$ The clinical manifestations of rickettsioses are different. The exanthematic rickettsioses syndrome with a centripedal rash and a low probability of inoculation eschar ( $R$. rickettsii) is seen as: (a) associated with a maculopapular/purpuric rash
(R. massiliae, R. parkeri, R.conorii, R. sibirica subsp. sibirica, $R$. heilongjiangensis, $R$. japonica, $R$. honei, $R$. aeschlimannii infection); (b) associated with a vesicular rash ( $R$. africae and $R$. australis infection); and (c) associated with regional lymphadenopathy (R. slovaca, $R$. raoultii and Rickettsia sp genotype $364 \mathrm{D}$ [R. philipii]) associated with lymphangitis $(R$. heilongjiangensis and $R$. africae). ${ }^{35}$

Culture is still accepted as the gold standard for diagnosing rickettsioses. This method is difficult as it requires a Biolevel 3 laboratory and trained staff. Current technology and molecular methods including PCR and quantitative PCR may also be used. ${ }^{36}$

Doxycycline is still an effective drug in rickettsial infections when administered for 1-7 days depending on the severity of the disease. Josamycin, clarithromycin, and azithromycin may be considered as alternative agents and administered for 7 days. ${ }^{37}$ If antibiotic therapy is initiated early, preferably during the first week of illness, the treatment is highly effective and is associated with the best outcome. ${ }^{31}$

\section{Viral Infections}

Arbovirus Infections

The major Arbovirus infections that cause human disease are divided into categories according to their vectors, such as mosquito, sand fly, and tick. ${ }^{38}$ The causes of tick-borne viral infections are the Flavivirus that belongs to the Flaviviridae family, the Nairovirus genus that belongs to the Bunyaviridae family, and the Coltivirus genus that belongs to the Reoviridae family. ${ }^{39}$ Table 3 outlines tick-borne arbovirus infections.

TBE is an important cause of infection among travelers that excursion to endemic regions between April and November. Hikers and campers are at a greater risk in forested areas at altitudes of about $1500 \mathrm{~m} \cdot{ }^{39,40}$ Baltic States, the Russian Federation, and Slovenia are known to have a high incidence of TBE. ${ }^{40}$ Outdoor recreation activities and wearing short trousers in areas of long grass are major risk factors in endemic georaphical areas. Recently, an increased incidence of TBE was attributed to more time being spent outdoors during warm weather. ${ }^{38,41}$

\section{Crimean-Congo Hemorrhagic Fever}

CCHF was described in soldiers of the Soviet Union in the Crimea region during the Second World War, and this disease was called Crimean fever. Because a patient with similar symptoms was reported in Congo in 1956, the name was changed to Crimean-Congo hemorrhagic fever in the 1970 s. $^{42}$

CCHF virus is a member of the Nairovirus genus within the Bunyaviridae family and has a triple segmented RNA genome. It is a negative-stranded, enveloped RNA virus. ${ }^{4,42}$ This genus contains only three pathogens in humans, like the Dugbe and Nairobi sheep disease viruses. ${ }^{43}$ A genetic relationship is associated with the neighborhood. For example, Balkan strains of CCHF are clustered in the same branch and are closely related to Turkish and Southwestern Russian strains. ${ }^{42,44}$ Although they are neighboring countries, strains found in Iran are not related to the Turkish clade. ${ }^{44}$

Common transmission routes of $\mathrm{CCHF}$ are tick bites and crushing ticks with uncovered hands. All sites of the human body, particularly the trunk, extremities, head, and neck are involved in tick attachment. ${ }^{45}$ Many domestic and wild 
Table 3. Tick-Borne Arbovirus Infections That Cause Human Disease

\begin{tabular}{|c|c|c|c|}
\hline Genus & Viral Disease & Main Host & Clinical Presentation \\
\hline \multirow[t]{7}{*}{ Flavivirus } & TBE & Rodents & Encephalitis \\
\hline & Central European encephalitis & Rodents & Encephalitis \\
\hline & Russian spring-summer encephalitis & Rodents & Encephalitis \\
\hline & Powassan & Rodents & Encephalitis \\
\hline & Louping-ill virus & Sheep, cattle, horses, grouses, and humans & Encephalitis \\
\hline & Omsk hemorrhagic fever & Water voles, muskrats & Hemorrhagic fever \\
\hline & Kyasanur Forest disease virus & Rodents, shrews, and monkeys & Hemorrhagic fever \\
\hline Nairovirus & Crimean-Congo hemorrhagic fever & Wild and domestic mammals & Hemorrhagic fever \\
\hline Coltivirus & Colorado tick fever & Small rodents and humans & Febrile illness \\
\hline
\end{tabular}

Abbreviation: TBE, tick-borne encephalitis.

animals, including cattle, sheep, goats, hedgehogs, and hares, have been identified as reservoirs for tick-borne viruses. ${ }^{43}$ The most important tick vector of CCHF is Hyalomma spp. Another transmission route in humans is close contact with the blood or body fluid of an infected animal or person. Farmers, health care workers (HCW), and slaughterhouse workers are at risk for CCHF. It is recorded that approximately $30 \%$ of patients cannot remember any tick exposure or bites. ${ }^{46,47}$ Person-to-person transmission is not an easy route for $\mathrm{CCHF}^{48}$

CCHF is transmitted by Hyalomma ticks which belong to the hard-bodied Ixodes family. ${ }^{42}$ The geographic distribution of Hyalomma ticks is limited to a latitude of $48^{\circ}$ north, which is the northern border of the world. ${ }^{49}$ Common reservoirs of adult ticks are livestock; however, larvae and nymphs feed on rodents and birds. Each tick can attach for 2-13 days; after feeding, the tick leaves the host. ${ }^{6}$ The duration of feeding for hard ticks varies according to the stage of life: 3-5 days for larvae, 4-8 days for nymphs, and 5-20 days for adult females. ${ }^{42,50}$ Female ticks remain inactive for the first 24 hours, then begin blood uptake. The virus begins to multiply within 36 hours of transmission. ${ }^{50}$

$\mathrm{CCHF}$ is an emerging and widely distributed disease. It is still an endemic or hyperendemic disease in the Balkan countries; the Caucuses and Middle Eastern countries such as Georgia, Turkey, and Iran; Africa; and some parts of Asian countries such as Russia, Pakistan, and Afghanistan. ${ }^{42,51}$ Since 2002, CCHF has been an emerging disease in Turkey. A total of 9787 cases were recorded by the Turkish Ministry of Health between 2002 and 2015. ${ }^{52}$ Although 2 cases of CCHF were reported in Germany in 2009, it was brought in from Afghanistan. ${ }^{53}$ Most recently, two CCHF cases were reported on August 31, 2016 by the health authorities in Madrid, Spain; thus, CCHF has reached a Mediterranean country. ${ }^{54}$

The incubation period varies from 1-13 days according to the type of transmission. It may shorten to 1-3 days following the tick bite, but it could also extend to 3-7 days after exposure through infected blood and body fluid. The clinical spectrum of the disease ranges from subclinical to mild to severe with fever, hemorrhage, and multiorgan failure (Figure 5). Most patients experience a subclinical form (88\%). ${ }^{46,55} \mathrm{CCHF}$ starts with a sudden onset of fever, headache, myalgia, dizziness, photophobia, ecchymosis, nausea, vomiting, and abdominal pain. ${ }^{4,46}$ In 2014-2015, 17 cases were admitted to the authors' clinic for CCHF; the mean age was 40.3 (range of 16-73) years, and 10 of them were male. All cases were people living in rural areas or working on farms and responsible for animal care. According to the severity scoring index (SSI) of Dokuzoguz, ${ }^{56} 6$ of 17 patients were mild cases, and 11 were moderate. The most common symptom was fever (94.1\%) followed by headache $(76.5 \%)$, nausea (58.8\%), vaginal bleeding, and hematuria or epistaxis (29.4\%). Furthermore, $70.6 \%$ of all patients had a history of tick bite. One published study reported that circulating plasma cell-free DNA was a biomarker predicting CCHF prognosis. ${ }^{57}$

The diagnosis of CCHF is based on the suspicion that patients come from endemic/hyperepidemic areas and have a history of tick bite. The Turkish healthcare authorities have published an algorithm for case definition and management. ${ }^{52}$ First, CCHF should be suspected in the case of presenting two situations: ( $i$ ) clinical findings indicate fever and bleeding, (ii) epidemiologic risk factors include travel to an endemic region within the previous two weeks and exposure to tick bite or contact with animal tissue or body fluids. ${ }^{42,52}$ In laboratory findings, leukopenia, thrombocytopenia, hemolisis, hyperbilirubinemia, and elevated transaminases are confirmed which clinically lead to bleeding diathesis. In severe cases, clinical and laboratory findings of disseminated intravascular coagulation and multiorgan failure may be observed. ${ }^{46}$ From clinical observations made by the authors between 2014-2015, 15 of 17 cases had leukopenia, 14 had a lower platelet count less than $100000 / \mathrm{mm}^{3}$, and 16 cases had elevated transaminase; only 2 cases had hyperbilirubinemia (bilirubine $>1 \mathrm{mg} / \mathrm{dL}$ ) (unpublished data).

For laboratory diagnoses, ELISA and RT-PCR methods are commonly used. Generally, a positive result is obtained by using PCR within the first 5 days of onset of the disease; ELISA-IgM positivity is generally seen after the fifth day. ${ }^{58,59}$ Studies using live CCHF virus should be performed in laboratories with a biosafety level of 3 or $4 .{ }^{42}$

Supportive therapy is very important in cases of CCHF. Antiviral therapy with ribavirin is also debatable. Although the WHO recommends the usage of ribavirin in both the treatment and prophylaxis of CCHF, there is no consensus on ribavirin therapy. ${ }^{42}$ It is noted that early initiation of ribavirin, i.e. during the viremia period, is more effective than late administration. ${ }^{56}$

Prevention and Control of Tick Borne-Infections Campers and hikers should be aware of tick-borne diseases 


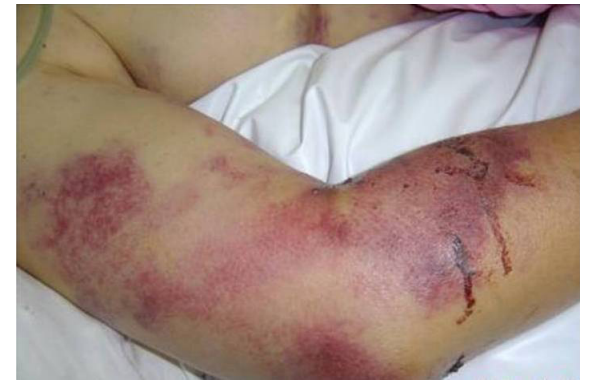

Figure 5. Wide-Spread Swelling and ecchimosis on the Right Arm Due to $\mathrm{CCHF}$.

Picture was kindly supplied by Professor Mehmet Bakir from Department of Infectious Diseases, Faculty of Medicine, Cumhuriyet University, Sivas/ Turkey.

while they spend time in endemic areas for these kinds of infections. They also should avoid tick-infested environments. Ticks are most active during the warmer months (AprilSeptember); people interested in outdoor activities should be extra careful during these times and should avoid greenwood areas with high grass. When camps are set up in endemic areas, applying herbicides or having a campfire may be useful. For the prevention of tick-borne infections, the application of general measures is the same in all kinds of vector-borne infections. To avoid tick bites, protective clothing is essential, especially for campers and hikers; clothing that covers the arms and legs should be worn, and clothing should be inspected twice a day to get rid of any unattached ticks. These precautions may be useful. Clothes, pants, socks, boots, and tents may be treated with products containing $0.5 \%$ permethrin. Various insect repellents may be used on exposed skin surfaces. If the tick bites a human, the attached tick should be removed promptly and gently with fine-tipped tweezers. The ticks should not be squeezed. It is suggested that a shower be taken within 2 hours of a tick bite. Campers and hikers should be careful about food and water consumption. They should not drink untreated water, especially from unknown sources, and they should avoid consuming raw meat. If campers hunt, trap, or skin wild animals (especially rabbits, muskrats, prairie dogs, and other rodents), they should wear gloves before touching the animals. Prophylactic doxycycline chemotherapy within 72 hours of a tick bite could be considered for immunosuppressed patients as a treatment for Lyme disease. Currently, there is no licensed vaccine for tularemia, Lyme, or ricketsiosis available for human usage. An inactivated vaccine is available for TBE. An inactivated virus vaccine from mouse brain was also prepared for CCHF in Russia, but it is not available in other countries. ${ }^{1,18,24,38,60}$

\section{Discussion}

Many people who live in well-developed countries enjoy spending time outdoors, especially in the United States. ${ }^{61-63}$ It is documented that an already large and increasing number of Americans enjoy spending time outdoors. Campers and hikers are exposed to health dangers while hiking or camping in the wilderness. However, few studies have been conducted on the health risks and overall healthcare of hikers or campers. Of the studies that have been carried out, most were in the United States. Feet blisters, diarrhea, skin irritation, and
Review Highlights

What Is Already Known?

Tick-borne infections are maintained in nature in complex transmission cycles that incidentally infect humans and cause disease. Outdoor recreational activities (walking, hiking, camping, etc.) are becoming more popular all over the world. Currently, some etiological agents transmitted by ticks may lead to the emergence or re-emergence of diseases in some parts of the world.

\section{What This Study Adds?}

For the prevention of tick-borne diseases, the authors believe that this paper will raise public and medical staff awareness. This is also comprehensive information for campers, climbers, hikers, and all sorts of travelers. It may also encourage public health and infectious diseases physicians' surveillance studies on these groups and will capture the attention of scientists and health professionals that are interested in this subject.

acute joint pain are the most frequently recorded complaints in these studies. The incidence of vector-borne disease has been given as $4 \%$, and Lyme disease has been diagnosed most commonly among tick-borne diseases. Tick bites are also most frequently recorded among hikers and campers. ${ }^{61,63,64}$

Many tick-borne infections, particularly CCHF and Tularemia, are endemic/hyperendemic in Middle Eastern countries. Recently, some local outbreaks of CCHF and Tularemia have been seen in Balkan countries, some parts of Turkey, Caucasian countries, and some parts of Iran. Cases generally come from rural and farming areas. ${ }^{46-48,52,58}$ Although CCHF and Tularemia are notifiable diseases in Turkey, there are not any case records for campers or hikers. For future studies, prospective or retrospective studies for tick-borne infections that focus on campers, hikers, climbers, and others should be conducted.

\section{Conclusion}

Outdoor recreational activities (walking, hiking, camping, etc.) are becoming more popular throughout the world. Vector-borne diseases are distributed by geographical region, seasonal weather, life cycle of vectors, reservoirs, and human behavior. One of the most important vectors is ticks. During outdoor recreational activities, humans are frequently exposed to ticks and are potentially at risk for tick-borne diseases. For prevention of tick-borne diseases, it is important that public and medical awareness is raised.

\section{Authors' Contributions}

The authors contributed equally to designing, preparing, drafting, and review of this manuscript. The final draft was also read and approved by the authors.

\section{Conflict of Interest Disclosures}

The authors have no conflicts of interest.

Ethical Approval

Not applicable. 


\section{Funding/Support}

The authors received no specific funding for this work.

\section{Acknowledgments}

The authors would like to thank Ms. Donna Sue Ozcan from the International Unit at the Genome and Stem Cell Center, Erciyes University, Kayseri, Turkey for her suggestions regarding the editing of this article, Professor Abdullah Inci from the Veterinary Faculty of Erciyes University for kindly supplying tick photos, and Professor Mehmet Bakir from the Faculty of Medicine of Cumhuriyet University for kindly supplying photos of CCHF patients.

\section{References}

1. Jacobs RF, Schutze GE. The camper's uninvited guests. In: Schlossberg DL, ed. Infections of Leisure. 3rd ed. Washington DC: ASM Press; 2004:119-135.

2. Natarajan $P$, Miller A. Recreational infections. In: Cohen J, Powderly WG, Opal SM, eds. Infectious Diseases. 4th ed. Elsevier; 2017:643-646.

3. Bratton RL, Corey R. Tick-borne disease. Am Fam Physician. 2005;71:2323-2330.

4. Bente DA, Forrester NL, Watts DM, McAuley AJ, Whitehouse CA, Bray M. Crimean-Congo hemorrhagic fever: history, epidemiology, pathogenesis, clinical syndrome and genetic diversity. Antiviral Res. 2013;100:159-189. doi:10.1016/j.antiviral.2013.07.006.

5. Beard CB, Eisen RJ, Barker CM, et al. Vectorborne Diseases. The Impacts of Climate Change on Human Health in the United States: A Scientific Assessment. Washington: U.S. Global Change Research Program; 2016. doi:10.7930/J0765C7V.

6. Centers for Disease Control and Prevention (CDC). Life cycle of Hard Ticks that Spread Disease. Atlanta: CDC; 2015. http://www. cdc.gov/ticks/life_cycle_and_hosts.html. Accessed June 1, 2015.

7. Shchuchinova LD, Kozlova IV, Zlobin VI. Influence of altitude on tick-borne encephalitis infection risk in the natural foci of the Altai Republic, Southern Siberia. Ticks Tick Borne Dis. 2015;6:322329. doi:10.1016/j.ttbdis.2015.02.005.

8. Broman T, Thelaus J, Andersson AC, et al. Molecular detection of persistent Francisella tularensis subspecies holarctica in natural waters. Int J Microbiol 2011;2011. doi:10.1155/2011/851946.

9. Lai XH, Zhao LF, Chen XM, Ren Y. Rapid identification and characterization of francisella by molecular biology and other techniques. Open Microbiol J. 2016;10:64-77. doi:10.2174/187 4285801610010064.

10. Guthrie AL, Gailbreath KL, Cienava EA, Bradway DS, Munoz Gutierrez JF. Septic tularemia in 2 cottontop tamarins (Sanguinus oedipus). Comp Med. 2012;62:225-228.

11. Kingry LC, Petersen JM. Comparative review of Francisella tularensis and Francisella novicida. Front Cell Infect Microbiol. 2014;4:35. doi:10.3389/fcimb.2014.00035.

12. Mitchell JL, Chatwell N, Christensen D, et al. Development of realtime PCR assays for the specific detection of Francisella tularensis ssp. tularensis, holarctica and mediaasiatica. Mol Cell Probes. 2010;24:72-76. doi:10.1016/j.mcp.2009.10.004

13. Ulu Kilic A, Doğanay M. Tularemia: a re-emerging disease. Vet J Ankara Univ. 2013;60:275-280.doi:10.1501/Vetfak_0000002592.

14. Ulu-Kilic A, Doganay M. An overview: tularemia and travel medicine. Travel Med Infect Dis. 2014;12:609-616. doi:10.1016/j. tmaid.2014.10.007.

15. Balci E, Borlu A, Kilic AU, Demiraslan H, Oksuzkaya A, Doganay M. Tularemia outbreaks in Kayseri, Turkey: an evaluation of the effect of climate change and climate variability on tularemia outbreaks. J Infect Public Health. 2014;7:125-132. doi:10.1016/j. jiph.2013.09.002.

16. Hodzic E. Lyme Borreliosis: is there a preexisting (natural) variation in antimicrobial susceptibility among Borrelia burgdorferi strains? Bosn J Basic Med Sci. 2015;15:1-13. doi:10.17305/ bjbms.2015.594.

17. Hou J, Ling F, Chai C, et al. Prevalence of Borrelia burgdorferi sensu lato in ticks from eastern China. Am J Trop Med Hyg. 2015;92:262-266. doi:10.4269/ajtmh.14-0587ajtmh.14-0587.

18. O'Connell S, Wolfs TF. Lyme borreliosis. Pediatr Infect Dis J. 2014;33:407-409. doi:10.1097/INF.0000000000000248.

19. Skotarczak B. Why are there several species of Borrelia burgdorferi sensu lato detected in dogs and humans? Infect Genet Evol. 2014;23:182-188. doi:10.1016/j.meegid.2014.02.014.

20. Szekeres S, Coipan EC, Rigo K, et al. Eco-epidemiology of Borrelia miyamotoi and Lyme borreliosis spirochetes in a popular hunting and recreational forest area in Hungary. Parasit Vectors. 2015;8:309. doi:10.1186/s13071-015-0922-2.

21. Aucott JN, Luft BJ. Lyme disease. In: Cohen J, Powderly WG, Opal SM, eds. Infectious Diseases. 4th ed. Elsevier; 2017:405-414.

22. Ogden NH, Feil EJ, Leighton PA, et al. Evolutionary aspects of emerging Lyme disease in Canada. Appl Environ Microbiol. 2015;81:7350-7359. doi:10.1128/AEM.01671-15.

23. Iyer R, Schwartz I. Microarray-based comparative genomic and transcriptome analysis of Borrelia burgdorferi. Microarrays (Basel). 2016;5(2):9. doi:10.3390/microarrays5020009.

24. Stanek G, Wormser GP, Gray J, Strle F. Lyme borreliosis. Lancet. 2012;379:461-473. doi:10.1016/S0140-6736(11)60103-7.

25. Fang LQ, Liu K, Li XL, et al. Emerging tick-borne infections in mainland China: an increasing public health threat. Lancet Infect Dis. 2015;15:1467-1479. doi:10.1016/S1473-3099(15)00177-2.

26. Ismail N, Bloch KC, McBride JW. Human ehrlichiosis and anaplasmosis. Clin Lab Med. 2010;30:261-292. doi:10.1016/j. cll.2009.10.004.

27. Thomas RJ, Dumler JS, Carlyon JA. Current management of human granulocytic anaplasmosis, human monocytic ehrlichiosis and Ehrlichia ewingii ehrlichiosis. Expert Rev Anti Infect Ther. 2009;7:709-722. doi:10.1586/eri.09.44.

28. Yabsley MJ. Natural history of Ehrlichia chaffeensis: vertebrate hosts and tick vectors from the United States and evidence for endemic transmission in other countries. Vet Parasitol. 2010;167:136-148. doi:10.1016/j.vetpar.2009.09.015S0304-4017(09)00548-2.

29. Paddock CD, Childs JE. Ehrlichia chaffeensis: a prototypical emerging pathogen. Clin Microbiol Rev. 2003;16:37-64.

30. McQuiston J. Infectious Diseases Related to Travel. Centers for Diseases Control and Prevention; 2015. http://wwwnc.cdc.gov/ travel/yellowbook/2016/infectious-diseases-related-to-travel/ rickettsial-spotted-typhus-fevers-related-infections-anaplasmosisehrlichiosis\#4695.

31. Raoult D. Introduction to rickettsioses, ehrlichioses, and anaplasmosis. In: Bennett JE DR, Blaser MJ, eds. Mandell, Douglas, and Bennett's Principles and Practice of Infectious Diseases, Updated Edition. 8th ed. Saunders; 2015:2194-2197.

32. Biggs HM, Behravesh CB, Bradley KK, et al. Diagnosis and management of tickborne rickettsial diseases: Rocky Mountain spotted fever and other spotted fever group rickettsioses, ehrlichioses, and anaplasmosis - United States. MMWR Recomm Rep. 2016;65:1-44. doi:10.15585/mmwr.rr6502a1.

33. Drexler NA, Dahlgren FS, Heitman KN, Massung RF, Paddock CD, Behravesh CB. National surveillance of spotted fever group rickettsioses in the United States, 2008-2012. Am J Trop Med Hyg. 2016;94:26-34. doi:10.4269/ajtmh.15-0472.

34. Parola P, Paddock CD, Socolovschi C, et al. Update on tickborne rickettsioses around the world:a geographic approach. Clin Microbiol Rev. 2013;26:657-702. doi:10.1128/CMR.00032-13.

35. Faccini-Martinez AA, Garcia-Alvarez L, Hidalgo M, Oteo JA. Syndromic classification of rickettsioses:an approach for clinical practice. Int J Infect Dis. 2014;28:126-139. doi:10.1016/j. ijid.2014.05.025.

36. Brouqui P, Bacellar F, Baranton G, et al. Guidelines for the diagnosis of tick-borne bacterial diseases in Europe. Clin Microbiol Infect. 2004;10:1108-1132. doi:10.1111/j.1469-0691.2004.01019.x.

37. Botelho-Nevers E, Socolovschi C, Raoult D, Parola P. Treatment of Rickettsia spp. infections:a review. Expert Rev Anti Infect Ther. 2012;10:1425-1437. doi:10.1586/eri.12.139.

38. Petersen LR, Ksiazek TG. Zoonotic viruses. In: Cohen J, Powderly WG, Opal SM, eds. Infectious Diseases. 4th ed. Elsevier; 2017:1493-1508.

39. Lani R, Moghaddam E, Haghani A, Chang LY, AbuBakar S, Zandi 
K. Tick-borne viruses: a review from the perspective of therapeutic approaches. Ticks Tick Borne Dis. 2014;5:457-465. doi:10.1016/j. ttbdis.2014.04.001.

40. World Health Organization. International travel and health: tick-borne encephalitis. http://www.who.int/ith/diseases/tbe/en/. Accessed October 5, 2016.

41. Jaenson TG, Hjertqvist M, Bergstrom T, Lundkvist A. Why is tickborne encephalitis increasing? A review of the key factors causing the increasing incidence of human TBE in Sweden. Parasit Vectors. 2012;5:184. doi:10.1186/1756-3305-5-184.

42. Leblebicioglu $H$. Crimean-Congo hemorrhagic fever. MA: Waltham; 2016. http://www.uptodate.com/contents/crimeancongo-hemorrhagic-fever. Accessed June 16, 2016

43. Soares-Weiser K, Thomas S, Thomson G, Garner P. Ribavirin for Crimean-Congo hemorrhagic fever:systematic review and metaanalysis. BMC Infect Dis. 2010;10:207. doi:10.1186/1471-233410-207.

44. Leblebicioglu H. Crimean-Congo haemorrhagic fever in Eurasia. Int J Antimicrob Agents. 2010;36 Suppl 1:S43-S46. doi:10.1016/j. ijantimicag.2010.06.020.

45. Gunduz A, Turkmen S, Turedi S, Nuhoglu I, Topbas M. Tick attachment sites. Wilderness Environ Med. 2008;19:4-6. doi:10.1580/06-WEME-BR-067.1

46. Yilmaz GR, Buzgan $\mathrm{T}$, Irmak $\mathrm{H}$, et al. The epidemiology of Crimean-Congo hemorrhagic fever in Turkey, 2002-2007. Int J Infect Dis. 2009;13:380-386. doi:10.1016/j.ijid.2008.07.02 1S1201-9712(08)01496-3.

47. Kalin G, Metan G, Demiraslan H, Doganay M. Do we really need ribavirin in the treatment of crimean-congo hemorrhagic Fever? J Chemother. 2014;26:146-149. doi:10.1179/1973947813Y.0000 000123 joc281.

48. Gozel MG, Bakir M, Oztop AY, Engin A, Dokmetas I, Elaldi $\mathrm{N}$. Investigation of Crimean-Congo hemorrhagic fever virus transmission from patients to relatives:a prospective contact tracing study. Am J Trop Med Hyg. 2014;90:160-162. doi:10.4269/ ajtmh.13-0306.

49. Papa A, Dalla V, Papadimitriou E, Kartalis GN, Antoniadis A. Emergence of Crimean-Congo haemorrhagic fever in Greece. Clin Microbiol Infect. 2010;16:843-847. doi:10.1111/j.14690691.2009.02996.x.

50. McGarry JW. Travel and disease vector ticks. Travel Med Infect Dis. 2011;9:49-59. doi:10.1016/j.tmaid.2011.01.002.

51. Mertens M, Schmidt K, Ozkul A, Groschup MH. The impact of Crimean-Congo hemorrhagic fever virus on public health. Antiviral Res. 2013;98:248-260. doi:10.1016/j.antiviral.2013.02.007.

52. Leblebicioglu H, Sunbul M, Guner R, et al. Healthcare-associated Crimean-Congo haemorrhagic fever in Turkey, 2002-2014: a multicentre retrospective cross-sectional study. Clin Microbiol
Infect. 2016;22:387. doi:10.1016/j.cmi.2015.11.024.

53. Conger NG, Paolino KM, Osborn EC, et al. Health care response to CCHF in US soldier and nosocomial transmission to health care providers, Germany, 2009. Emerg Infect Dis. 2015;21:23-31. doi:10.3201/eid2101.141413.

54. Jansa J. Crimean-Congo haemorrhagic fever in Spain. Stockholm: European Centre for Disease Prevention and Control; 2016. http://ecdc.europa.eu/en/publications/Publications/crimeancongo-haemorrhagic-fever-spain-risk-assessment.pdf. Updated September 8, 2016

55. Bodur H, Akinci E, Ascioglu S, Onguru P, Uyar Y. Subclinical infections with Crimean-Congo hemorrhagic fever virus, Turkey. Emerg Infect Dis. 2012;18:640-642. doi:10.3201/ eid1804.111374.

56. Dokuzoguz B, Celikbas AK, Gok SE, Baykam N, Eroglu MN, Ergonul O. Severity scoring index for Crimean-Congo hemorrhagic fever and the impact of ribavirin and corticosteroids on fatality. Clin Infect Dis. 2013;57:1270-1274. doi:10.1093/cid/cit527.

57. Bakir M, Engin A, Kuskucu MA, Bakir S, Gundag O, Midilli K. Relationship of plasma cell-free DNA level with mortality and prognosis in patients with Crimean-Congo hemorrhagic fever. J Med Virol. 2016;88:1152-1158. doi:10.1002/jmv.24446.

58. Uyar $\mathrm{Y}$, Carhan A, Albayrak N, Altas AB. [Evaluation of PCR and ELISA-IgM results in the laboratory diagnosis of Crimean-Congo haemorrhagic fever cases in 2008 in Turkey]. Mikrobiyol Bul. 2010;44:57-64.

59. Atkinson B, Chamberlain J, Logue $\mathrm{CH}$, et al. Development of a real-time RT-PCR assay for the detection of Crimean-Congo hemorrhagic fever virus. Vector Borne Zoonotic Dis. 2012;12:786793. doi:10.1089/vbz.2011.0770.

60. Gozel MG, Dokmetas I, Oztop AY, Engin A, Elaldi N, Bakir M. Recommended precaution procedures protect healthcare workers from Crimean-Congo hemorrhagic fever virus. Int J Infect Dis. 2013;17:e1046-e1050. doi:10.1016/j.ijid.2013.05.005.

61. Kellogg DS, Rosenbaum PF, Kiska DL, Riddell SW, Welch TR, Shaw J. High fecal hand contamination among wilderness hikers. Am J Infect Control. 2012;40:893-895. doi:10.1016/j. ajic.2011.11.009.

62. Mason RC, Suner S, Williams KA. An analysis of hiker preparedness: a survey of hiker habits in New Hampshire. Wilderness Environ Med. 2013;24:221-227. doi:10.1016/j.wem.2013.02.002.

63. Reed BC, Rasnake MS. An assessment of coliform bacteria in water sources near appalachian trail shelters Within the Great Smoky Mountains National Park. Wilderness Environ Med. 2016;27:107110. doi:10.1016/j.wem.2015.09.019.

64. Boulware DR, Forgey WW, Martin WJ. Medical risks of wilderness hiking. Am J Med. 2003;114:288-293. doi:10.1016/S00029343(02)01494-8. 